\title{
Corrosion Inhibition Effects of Some New Synthesized N-Aroyl-N-Aryl thiourea Derivatives for Carbon Steel in Sulfuric Acid Media
}

\author{
Uday H. R. Al-Jeilawi*, Suaad M. H. Al-Majidi and Khulood A. S. Al-Saadie \\ Department of Chemistry, College of Science, University of Baghdad, Baghdad-Iraq. \\ E-mail: dr.oday2009@gmail.com.
}

\begin{abstract}
This research includes the synthesis of some new $\mathrm{N}$-Aroyl- $\mathrm{N}^{\prime}$-Aryl thiourea derivatives namely: $\mathrm{N}$-benzoyl-N'-(p-aminophenyl) thiourea (STU1), N-benzoyl-N'-(thiazole) thiourea (STU2), $\mathrm{N}$-acetyl-N'-(dibenzyl) thiourea (STU3). The series substituted thiourea derivatives were prepared from reaction of acids with thionyl chloride then treating the resulted with potassium thiocyanate to affored the corresponding $\mathrm{N}$-Aroyl isothiocyanates which direct reaction with primary and secondary aryl amines, The purity of the synthesized compounds were checked by measuring the melting point and Thin Layer Chromatography (TLC) and their structure, were identified by spectral methods [FTIR, ${ }^{1} \mathrm{H}-\mathrm{NMR}$ and ${ }^{13} \mathrm{C}-\mathrm{NMR}$ ]. These compounds were investigated as a corrosion inhibitor for carbon steel in $1 \mathrm{M} \mathrm{H}_{2} \mathrm{SO}_{4}$ solution using weight loss, potentiostatic polarization methods; the obtained results showed that the substituted thioureas retard both cathodic and anodic reactions in acid media, by virtue of adsorption on the carbon steel surface. This adsorption obeyed Langmuir's adsorption isotherm. The inhibition efficiency of (STU1-3) is ranging between (60-95)\%. By using different (STU3) derivative concentration and temperature, the carbon steel corrosion rate was decreased with increasing (STU3) concentration and the highest inhibition efficiency reach to $98.5 \%$ by using $5 \times 10^{-4} \mathrm{M}$ (STU3) concentration at $338 \mathrm{~K}$, the inhibition efficiency increases with increasing temperature in the range of (308-338)K.
\end{abstract}

Keywords: thiourea derivatives, carbon steel, polarization, corrosion inhibition.

\section{Introduction}

Carbon steel is a very prominent material of construction and frequently comes in contact with aqueous solution, which may be acidic in nature, as a part of industrial process[1]. The study of corrosion of steel in acid media is of both academic and industrial significance that has received considerable attention[2,3]. Acid solution are widly used in industry, the most important fields of application being acid pickling, industrial acid cleaning, acid descaling, gas and oil well acidizing[4]. Acids are also used in numerous manufacturing processes in different industries [5]. Most of the efficient inhibitors used in industry are organic compounds [6]. The addition of inhibitors to the acid media has been found to be cost-effective way of mitigating metallic corrosion under conditions of moderate acid concentration and temperature [7]. The effect of temperature on the inhibiting process is of great importance in industry. Most of the well-known acid inhibitors are compound containing heteroatom phosphorus, sulfur, nitrogen and oxygen, which are capable of retarding metallic corrosion [8]. Generally, N-containing inhibitor functions more efficient in $\mathrm{HCl}$, while S-containing inhibitor in $\mathrm{H}_{2} \mathrm{SO}_{4}$ [9]. Furthermore, the compounds containing both $\mathrm{N}$ and $\mathrm{S}$ can provide excellent inhibition, compared with compounds containing only $\mathrm{N}$ or $S$ [10]. There are many investigations about thiourea and various thiourea derivatives as good inhibitors of the corrosion of iron or steel in $\mathrm{HCl}$ [11-13], $\mathrm{H}_{2} \mathrm{SO}_{4}$ [14-16], $\mathrm{HNO} 3$ [17], $\mathrm{HClO}_{4}$ [18], $\mathrm{H}_{3} \mathrm{PO}_{4}$ [19]. Such compounds can adsorb on the surface of the metal, blocking the active centers on the surface and thus reduces the corrosion rate [20]. The inhibition performance of organic inhibitors is due to physisorption and/or chemisorption on the surface of the metals [21, 22].

In this research some new thiourea derivatives (STU1-3) were synthezied; then evaluated as corrosion inhibitors for carbon steel in $1 \mathrm{M} \mathrm{H}_{2} \mathrm{SO}_{4}$ solution. weight loss and potentiostatic polarization have been used to determine; surface coverage $(\theta)$, inhibition efficiency (\% IE) and the inhibitor adsorption 
isotherm on carbon steel in the corrosive media.

\section{Experimental \\ Instruments}

Melting points were measured with a Gallen Kamp melting point apparatus. Model the FTIR-spectra of compounds were recorded on a Shimadzu FTIR-8300 spectrophotometer using $\mathrm{KBr}$ disc. ${ }^{1} \mathrm{HNMR}$ and ${ }^{13} \mathrm{CNMR}$ spectra were recorded on Bruker spectro spin ultra-shield magnets $300 \mathrm{MHz}$ instrument, using DMSO- $\mathrm{d}^{6}$ as solvent and TMS as internal reference. The Weight loss were measured with Sartorius Ag. Gottigen BL210S (Germany) Electronic precision balance and preions metal scale with capacities ranging $0.1 \mathrm{mg}$ to $12 \mathrm{~kg}$.

Polarization measurements were conducted using advanced potentiostat winking MLab-200 (2007) [Bank ElektronikIntelligent controls $\mathrm{GmbH}]$ with all accessories, a three electrodes cell were used. The working polished carbon steel electrode with exposed area $1 \mathrm{~cm}^{2}$ was dipped in the test solution. A saturated calomel electrode (SCE) and a platinum electrode were used as the reference and the counter electrodes, respectively. All potentials were measured vs. SCE.

\section{Chemicals}

All Starting chemical compounds were obtained from Fluka and Aldrich or BDH.

\section{synthesis of N-Aroyl-N-Aryl thiourea derivatives (STU1-3)[23]}

A solution of acid chloride was synthesized according to literature procedure $(0.01$ mole $)$ dissolved in dry acetone $(30 \mathrm{ml})$ was added dropwise to a suspension of potassium thiocyanate $(0.01$ mole, $0.9710 \mathrm{gm})$ in dry acetone $(30 \mathrm{ml})$, the reaction mixture was refluxed for $1 \mathrm{hr}$. After cooling to room temperature, a solution of primary and secondary aryl amines (0.01 mole) in dry acetone $(20 \mathrm{ml})$ was added and the resulting mixture refluxed for 3-4 hrs., then the reaction mixture was poured into cold water and the precipitated thioureas were recrystallized aqueous ethanol or ethanol, to afford the pure compounds (STU1-3).Some of the measured physical properties of the dry products are listed in Table (1).

Table (1)

Physical properties and FTIR spectral of compounds (STU1-3).

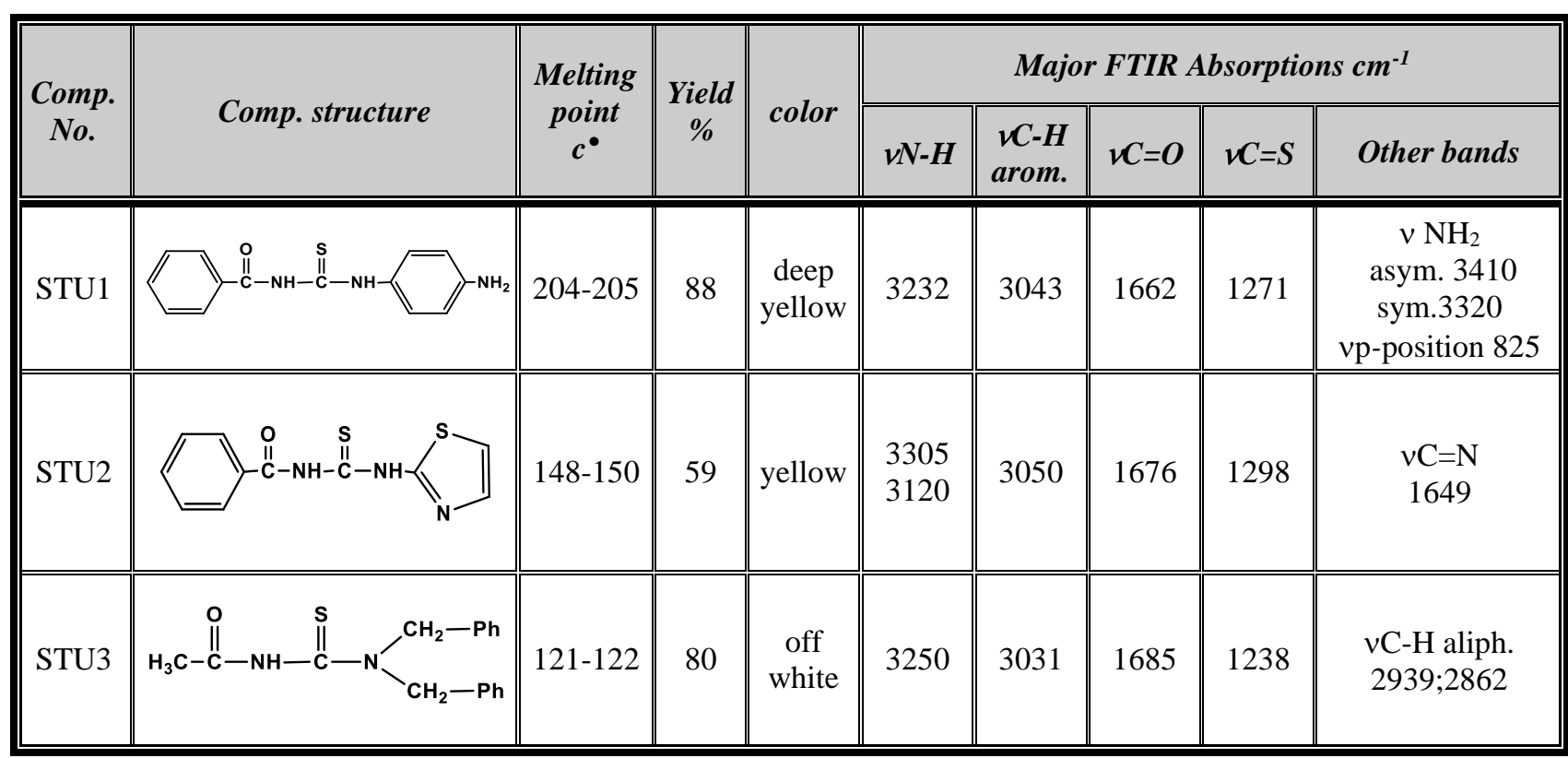

\section{Specimen}

Carbon steel specimens with composition $0.086 \% \mathrm{C}, 0.252 \% \mathrm{Mn}, 0.003 \% \mathrm{P}, 0.016 \% \mathrm{~S}$ and the remainder being $\mathrm{Fe}$ were used. Specimens of size $2 \mathrm{~cm} \times 1 \mathrm{~cm} \times 0.2 \mathrm{~cm}$ were used for the weight loss and of $1.5 \mathrm{~cm}$ diameter specimen were used for polarization method. These samples were polished successively with belt grinding polishing machine and polished with emery papers of different grit 
$(80,150,220,240,320,400,1000,1200$ and 2000) in sequence. After polishing the specimens were washed with distilled water and finally dried.

\section{Weight loss method}

Weight loss was carried out in a glass vessel containing $75 \mathrm{ml}$ test solution. A clean weighed carbon steel specimen was completely immersed at an inclined position in the vessel. After a period of time up to 5 hour at $303 \pm 1 \mathrm{k}$ of immersion in $1 \mathrm{M} \mathrm{H}_{2} \mathrm{SO}_{4}$ with and without addition of inhibitor (STU1-3), the specimen was withdrawn, rinsed with distilled water, washed with acetone, dried and weighted using the analytical balance. The average weight loss for each two identical experiments was taken and expressed in $\left(\mathrm{g} / \mathrm{m}^{2} \cdot \mathrm{d}\right)$.

\section{Potentiostatic polarization study}

The electrode potential was allowed to stabilize $15 \mathrm{~min}$ before starting the measurements. Tafel polarization curves were obtained by changing the electrode potential automatically from $-200 \mathrm{mV}$ versus open circuit potential (OCP) to $+200 \mathrm{mV}$ versus OCP with scan rate of $2.0 \mathrm{mV} \mathrm{s}^{-1}$. All experiments were conducted at $308 \pm 1 \mathrm{~K}$.Inhibitor concentration of $\left(1.7 \times 10^{-4}\right.$, $\left.3.5 \times 10^{-4}, 5 \times 10^{-4}\right) \mathrm{M}$ were examined. Tafel lines of potential versus, $I_{\text {corr }}$ in a logarithm scale were plotted and corrosion current density $\left(\mathrm{I}_{\text {corr }}\right)$ and corrosion potential $\left(\mathrm{E}_{\text {corr }}\right)$ were determined in the absence and presence of inhibitor.

\section{Corrosion inhibitors synthesis}

Most of the hetero compounds are very important organic compound having wide spectrum of corrosion inhibitors of carbon steel in acid media. The initial mechanism in any corrosion inhibition process is the adsorption of the inhibitor on the metal surface and can be facilitated by the presence of hetro atoms such as (N,O,P and S) [8]. Therefore, there is need for preparation of new organic compounds containing ( $\mathrm{N}$ and $\mathrm{S}$ ) atom for used as a corrosion inhibitors. The synthetic sequence leading to the thioureas(STU1-3) show in Scheme (1). All thioureas (STU1-3) were synthesized according to the method in previous paper [23] with minor modifications.
The obtained yields ranging from (59-88)\%. The synthesis involves acids converted into corresponding acid chlorides by treatment with thionyl chloride according to standard procedure. The acid chlorides were treated with an equimolar quantity of potassium thiocyanate in dry acetone to afford the corresponding isothiocyanates intermediates which were direct addition of an equimolar of primary and secondary aryl amines in dry acetone to isothiocyantes furnished the N-Aroyl-N'-Aryl thiourea derivatives (STU1-3). The reaction proceeds via a nucleophilic addition of the amine to the isothiocyanates, and the end point of the reaction was examined by TLC. The structure of these compounds (STU1-3) were confirmed by physical properties are listed in Table (1), and characterized by FTIR, 1H-NMR and 13C-NMR spectroscopy. FT-IR (KBr) spectra showing strong $\mathrm{vN}-\mathrm{H}$ absorptions at about $3305-3120 \mathrm{~cm}-1$, and displayed absorptions at about $1685-1662 \mathrm{~cm}-1$ and $1298-1238 \mathrm{~cm}-1$ that were assigned to $v \mathrm{C}=\mathrm{O}$ and $v \mathrm{C}=\mathrm{S}$ functions respectively. While the ${ }^{1} \mathrm{H}-\mathrm{NMR}$ spectra data of compounds (STU1-3) [24] $\delta \mathrm{ppm}$ in DMSO- $\mathrm{d}^{6}$ solvent are listed in Table (2). The signals in the range of 10.7$12.8\left[\mathrm{~S}, 1 \mathrm{H},{ }^{\stackrel{\mathrm{C}}{\mathrm{C}}-\mathrm{NH}-}\right] ; \quad 10.5-12.2 \quad[\mathrm{~S}, 1 \mathrm{H}$, -C-NH-]. Generally the1 H-NMR signals of $\mathrm{NH}$ protons for amides are observed in the range of [9-10] $\delta \mathrm{ppm}$. The low-field shift of the signal for the imine proton for synthesized compounds can be attributed to the deshielding effect of the electron-withdrawing carbonyl and thiocarbonyl group. 13C-NMR spectra data were listed in Table (3), spectrum showed the peaks at about $\delta$ 182.7-178.1 and 168.1-164.3 for $\mathrm{C}=\mathrm{S}$ (thioamide) and $\mathrm{C}=\mathrm{O}$ (amide), respectively. 
Uday H. R. Al-Jeilawi

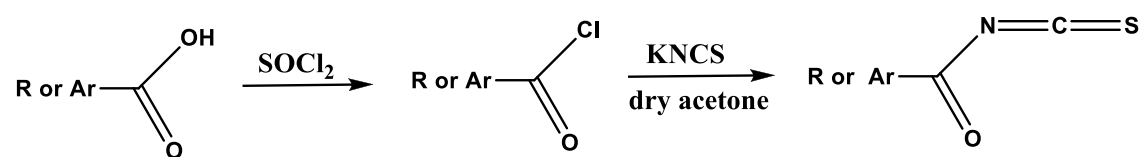

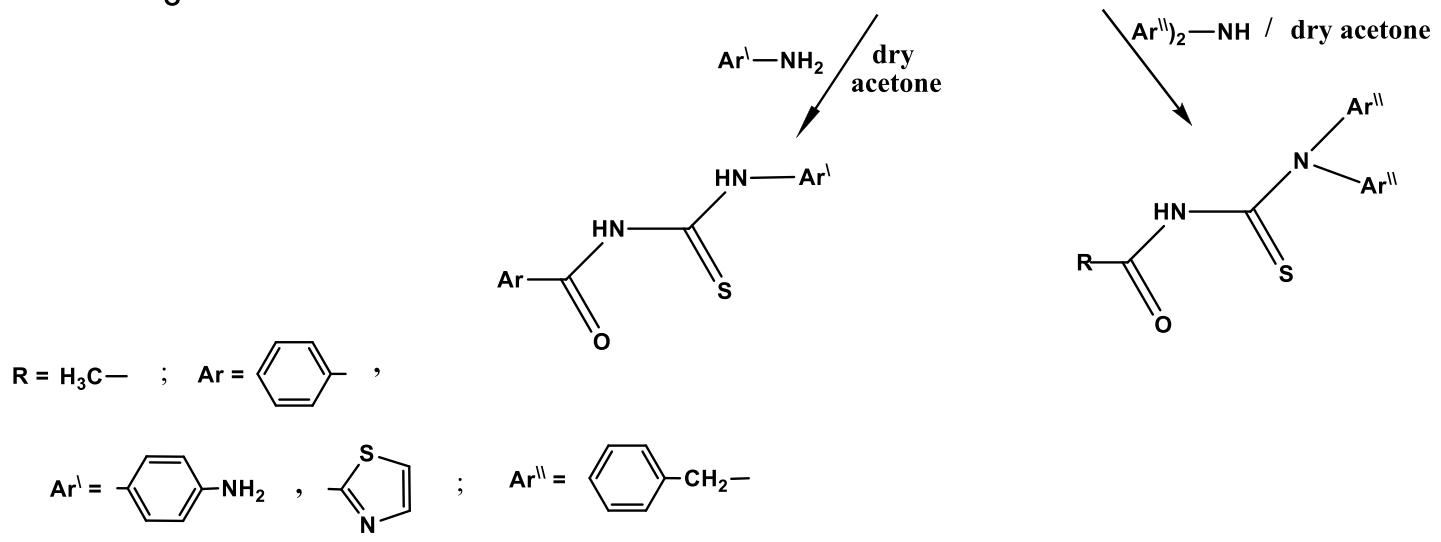

Scheme (1): synthesis of some new N-Aroyl-N'-Aryl thioureas

Table (2)

${ }^{1}$ H-NMR spectral data(ppm) for some of the prepared compounds (STU1-3).

\begin{tabular}{|c|c|c|}
\hline Comp. No. & Compound structure & ${ }^{1} H-N M R$ parameters (ppm) $\delta-H$ \\
\hline STU1 & & $\begin{array}{c}5.18\left(\mathrm{~s}, 2 \mathrm{H},-\mathrm{NH}_{2}\right) ; 6.5-7.9(\mathrm{~m}, 9 \mathrm{H}, \mathrm{Ar}-\mathrm{H}) \\
\mathbf{s} \\
10.5(\mathrm{~s}, 1 \mathrm{H},-\stackrel{\mathrm{C}}{\mathrm{C}}-\mathrm{NH}-) ; 11.32(\mathrm{~S}, 1 \mathrm{H},-\stackrel{\mathrm{C}}{\mathrm{C}}-\mathrm{NH}-)\end{array}$ \\
\hline STU2 & & $\begin{array}{l}\text { 7.27-7.36(d,2H,H-thiazole }) ; 7.5-8.6(\mathrm{~m}, 5 \mathrm{H}, \mathrm{Ar}-\mathrm{H}) ; 12.2(\mathrm{~s}, 1 \mathrm{H}, \\
\mathrm{s} \\
\left.{ }_{-\mathrm{C}}^{\|}-\mathrm{NH}-\right) ; 12.8(\mathrm{~S}, 1 \mathrm{H},-\mathrm{C}-\mathrm{NH}-)\end{array}$ \\
\hline STU3 & $\stackrel{\mathrm{O}}{\mathrm{C}}-\mathrm{NH}-\stackrel{\mathrm{s}}{\mathrm{C}}-\mathrm{N}-\mathrm{CH}_{\mathrm{CH}_{2}}$ & $\begin{array}{l}2.00\left(\mathrm{~s}, 3 \mathrm{H},-\mathrm{CH}_{3}\right) ; 4.63-5.13\left(\mathrm{~s}, 4 \mathrm{H},-\mathrm{CH}_{2}-\right) ; 7.15-7.35(\mathrm{~m}, 10 \mathrm{H}, \mathrm{Ar}- \\
\mathrm{H}) ; 10.59(\mathrm{~s}, 1 \mathrm{H},-\mathrm{NH}-)\end{array}$ \\
\hline
\end{tabular}

Table (3)

${ }^{13} \mathrm{C}-N M R$ spectral data for some of the prepared compounds(STU1-3).

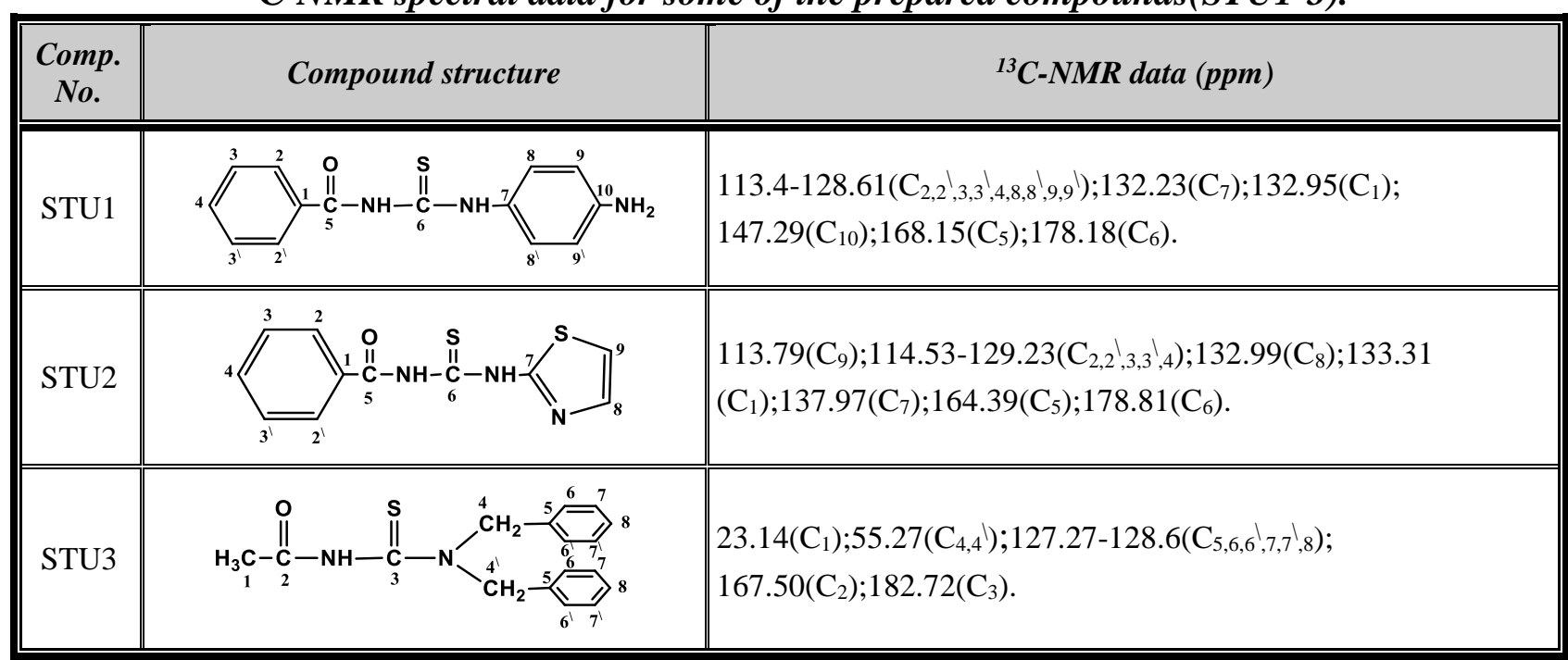




\section{Weight loss measurements}

The gravimetric measurements of carbon steel immersed in $1 \mathrm{M} \mathrm{H}_{2} \mathrm{SO}_{4}$ in the absence and presence of different inhibitors of thiourea derivatives (STU1-3) were investigated and determined after 4 hour of immersion time at $303 \mathrm{~K}, 3.5 \times 10^{-4} \mathrm{M}$ concentration of these inhibitors was chosen to compare the inhibition efficiency of the three compounds, weight loss of carbon steel samples are decreased in the present of the three compounds. This means that these compounds retards the corrosion of carbon steel in $1 \mathrm{M} \mathrm{H}_{2} \mathrm{SO}_{4}$ or in other words, these compounds act as inhibitors. The corrosion rate of carbon steel was determined using the relation:

$\mathbf{R}=\frac{\Delta \mathbf{m}}{\mathbf{A} * \mathbf{t}}$

where $\Delta m$ is the mass loss (mg), A the area $\left(\mathrm{cm}^{2}\right)$ and $\mathrm{t}$ immersion period (4 hours). The value of the percentage inhibition efficiency (\% IE), and a parameter surface coverage $(\theta)$ which represents the part of the surface covered by the inhibitors molecules, for the corrosion of carbon steel were calculated as follows [25]:

$$
\begin{aligned}
& \% \mathrm{IE}=\frac{\left(\mathbf{R}-\mathbf{R}_{\mathrm{inh}}\right)}{\mathbf{R}} \times 100 \\
& \boldsymbol{\theta}=\frac{\left(\mathbf{R}-\mathbf{R}_{\text {inh }}\right)}{\mathbf{R}}
\end{aligned}
$$

where $\mathrm{R}$ and $\mathrm{R}_{\text {inh }}$ are the uninhibited and the inhibited corrosion rate, respectively. The calculated values of corrosion rate $\left(\mathrm{g} / \mathrm{m}^{2} . \mathrm{d}\right)$, surface coverage $(\theta)$ and inhibition efficiency (\% IE) at $303 \mathrm{~K}$ are given in Table (4). According to this data, it is clear that using $3.5 \times 10^{-4} \mathrm{M}$ of all thiourea derivatives reduces the corrosion rate of carbon steel in sulfuric acid solution, the order of inhibition efficiency (\% IE) of investigated thioureas is as follows: STU3> STU2> STU1.
Table (4)

Data of corrosion rate, degree of surface coverage and inhibition efficiency for carbon steel in $1 \mathrm{M} \mathrm{H}_{2} \mathrm{SO}_{4}$ solution in the absence and presence of $3.5 \times 10^{-4} \mathrm{M}$ of the three inhibitors at $303 \mathrm{~K}$.

\begin{tabular}{|c||c||c||c||}
\hline inhibitor & $\boldsymbol{R}\left(\boldsymbol{g} / \mathbf{m}^{2} . \boldsymbol{d}\right)$ & $\boldsymbol{\theta}$ & \% IE \\
\hline \hline blank & 474.46 & -- & -- \\
\hline STU1 & 99 & 0.79 & 79.12 \\
\hline STU2 & 86.22 & 0.81 & 81.82 \\
\hline STU3 & 21.37 & 0.95 & 95.49 \\
\hline
\end{tabular}

\section{Polarization measurements}

Potentiostatic polarization curves were plotted for the corrosion of carbon steel in $1 \mathrm{M}$ $\mathrm{H}_{2} \mathrm{SO}_{4}$ solution in the absence and presence of $3.5 \times 10^{-4} \mathrm{M}$ thioureas (STU1-3) at $308 \mathrm{~K}$ as shown in (Fig. (1)).

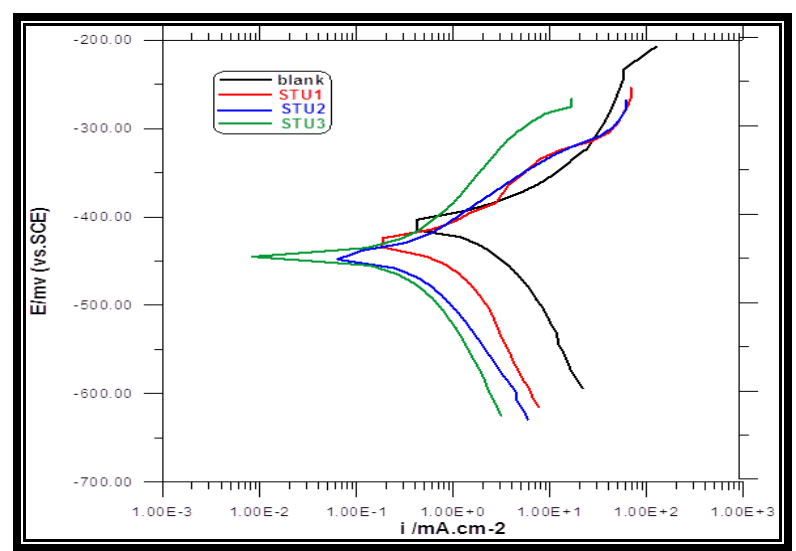

Fig.(1) Polarization curves of carbon steel in $\mathrm{IM} \mathrm{H}_{2} \mathrm{SO}_{4}$ in the absence and presence of $3.5 \times 10^{-4} \mathrm{M}$ thioureas (STU1-3) at $308 \mathrm{~K}$.

A linear region with apparent Tafel was observed, the cathodic reaction was activationcontrolled and the addition of the compounds tested decreased the current densities in large anodic and cathodic domains of potential. This result indicated that the compounds studied acted as mixed-type inhibitors. Generally, the addition of mixed inhibitors in solution does not change corrosion potential significantly because they inhibit both the anodic and cathodic reactions. Small changes in potentials can be a result of the competition of the anodic and the cathodic inhibiting reactions, and of the metal surface condition [26]. The values of various electrochemical parameters are summarized in Table (5), the percentage 
inhibition efficiency (\% IE), and a parameter surface coverage $(\theta)$ which represents the part of the surface covered by the inhibitors molecules, for the corrosion of carbon steel were calculated as follows [27]. Where $\mathrm{I}_{\text {corr }}$ and $\mathrm{I}_{\text {corr(inh) }}$ are the corrosion currents densities in the absence and in presence of the inhibitor,respectively which determined by extrapolation of the cathodic and anodic Tafel lines to corrosion potential ( $\left.\mathrm{E}_{\text {corr }}\right)$.From Table (5), it was clearly seen that cathodic slope were found similar indicating that the reduction of hydrogen did not modified in the presence of the inhibitors tested.Thus, the presence $3.5 \times 10^{-4} \mathrm{M}$ of thioureas led to decrease in the values of $\mathrm{I}_{\text {corr }}$, which was particularly significant in the case of( STU3).

Table (5)

polarization parameters of carbon steel in $1 \mathrm{M} \mathrm{H}_{2} \mathrm{SO}_{4}$ in the absence and presence of $3.5 \times 10^{-4} \mathrm{M}$ thioureas (STU1-3) at $308 \mathrm{~K}$.

\begin{tabular}{|c|c|c|c|c|c|c|c|c|}
\hline Solution & $\begin{array}{c}\boldsymbol{E}_{c o r r} \\
\boldsymbol{m} \boldsymbol{v} \\
(S C E)\end{array}$ & $\begin{array}{c}I_{\text {corr }} \\
\mu A / \mathrm{cm}^{2}\end{array}$ & $\begin{array}{c}\beta c \\
m V / d e c\end{array}$ & $\begin{array}{c}\beta a \\
m V / d e c\end{array}$ & $\begin{array}{c}W . L \\
g / m^{2} . d\end{array}$ & $\begin{array}{c}\text { Penetration } \\
\text { loss } \\
m m / a\end{array}$ & $\theta$ & $\% I E$ \\
\hline blank & -411.8 & 1450 & -109.2 & 70.5 & 363 & 16.9 & -- & -- \\
\hline STU1 & -429.8 & 585.93 & -123.2 & 79.6 & 146 & 6.80 & 0.5959 & 59.59 \\
\hline STU2 & -443.4 & 281.27 & -107.5 & 73.7 & 703 & 3.26 & 0.8060 & 80.60 \\
\hline STU3 & -448.4 & 236.24 & -112.0 & 105.1 & 59.1 & 2.74 & 0.8370 & 83.70 \\
\hline
\end{tabular}

\section{Effect of inhibitor (STU3) concentration}

Effect $\mathrm{N}$-acetyl-N'-(dibenzyl) thiourea (STU3) was investigated in the concentration range $\left(1.7 \times 10^{-4}-5 \times 10^{-4}\right) \mathrm{M}$. (Fig. (2)) shows the Tafel polarization value of carbon steel immersed in $1 \mathrm{M} \mathrm{H}_{2} \mathrm{SO}_{4}$ at $308 \mathrm{~K}$ with and without (STU3) inhibitor. polarization parameters such as corrosion potential $\left(\mathrm{E}_{\mathrm{corr}}\right)$, cathodic and anodic Tafel slopes $(\beta c$ and $\beta a)$ and corrosion current density ( $\left.\mathrm{I}_{\text {corr }}\right)$ were extracted by extrapolating the anodic and cathodic branches of Tafel curves at potentials beyond the region of Ecorr $\pm 200 \mathrm{mV}$, and are listed in Table (6). From the results collected in Table (6), it can be seen that by increasing the inhibitor concentration, the corrosion rate is decreased in acid media and inhibition efficiency increased as shown in Fig.(3). Therefore, it can be concluded that they impede the corrosion by merely blocking the reaction sites on carbon steel surface without interfering the anodic and cathodic reactions. Moreover, this inhibitor cause no significant changes in the anodic and cathodic Tafel slopes, this suggest that this inhibitor behave as a mixed-type inhibitor. Indicating that the inhibitor can be classified as adsorptive-type [26].

Table (6)

Polarization parameters of carbon steel in $1 \mathrm{M} \mathrm{H}_{2} \mathrm{SO}_{4}$ in the absence and presence of different concentrations of (STU3) at $308 \mathrm{~K}$.

\begin{tabular}{|c|c|c|c|c|c|c|c|c|}
\hline $\begin{array}{l}\text { Inhibitor } \\
\text { conc. } \\
(M)\end{array}$ & $\begin{array}{c}E_{c o r r} \\
\boldsymbol{m} v \\
(S C E)\end{array}$ & $\begin{array}{c}I_{\text {corr }} \\
\mu A / \mathrm{cm}^{2}\end{array}$ & $\begin{array}{c}\beta c \\
m V / d e c\end{array}$ & $\begin{array}{c}\beta a \\
m V / d e c\end{array}$ & $\begin{array}{c}W . L \\
g / m^{2} . d\end{array}$ & $\begin{array}{c}\text { Penetration } \\
\text { loss } \\
m m / a\end{array}$ & $\theta$ & $\% I E$ \\
\hline 0 & -411.8 & 1450 & -109.2 & 70.5 & 363 & 16.9 & -- & -- \\
\hline $1.7 \times 10^{-4}$ & -454.9 & 456.44 & -151.8 & 123.5 & 114 & 5.30 & 0.6852 & 68.52 \\
\hline $3.5 \times 10^{-4}$ & -448.4 & 236.24 & -112.0 & 105.1 & 59.1 & 2.74 & 0.8370 & 83.70 \\
\hline $5 \times 10^{-4}$ & -458.8 & 206.92 & -73.6 & 64.4 & 51.7 & 2.40 & 0.8572 & 85.72 \\
\hline
\end{tabular}




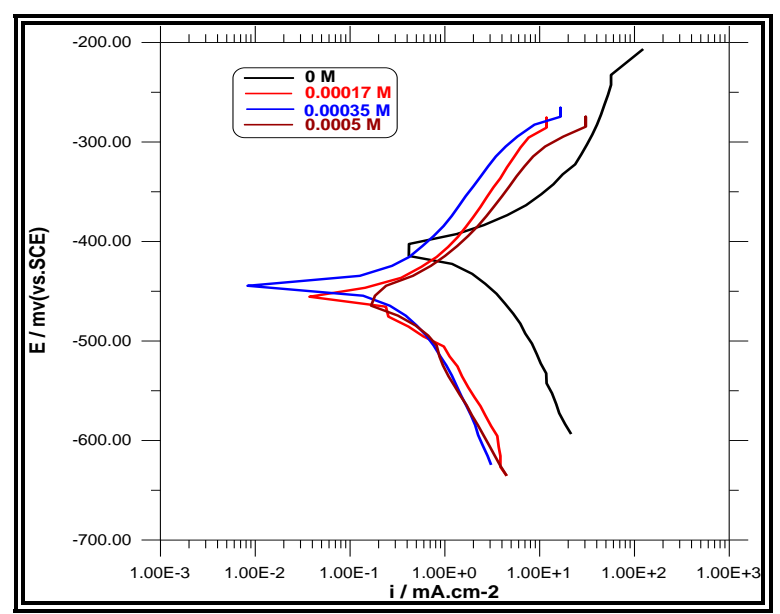

Fig.(2) Polarization curves of carbon steel in $1 \mathrm{M} \mathrm{H}_{2} \mathrm{SO}_{4}$ in the absence and presence of inhibitor (STU3) different concentration at $308 \mathrm{~K}$.

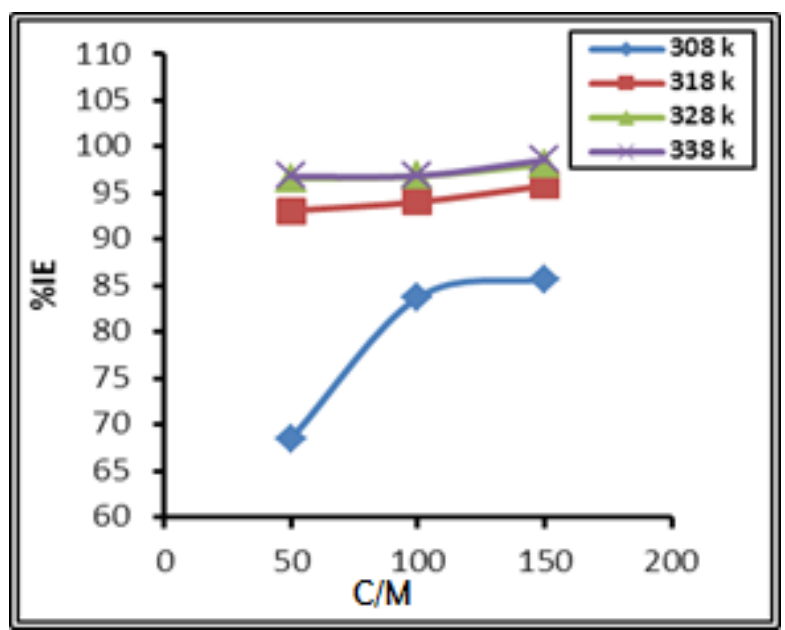

Fig.(3) Relationship between inhibition efficiencies and various concentrations from inhibitor(STU3) for carbon steel in $1 M$ $\mathrm{H}_{2} \mathrm{SO}_{4}$.

\section{Adsorption isotherms}

Basic information on the interaction between inhibitors and metal surface can be provided using the adsorption isotherms [28]. The adsorption of an organic adsorbate at metal-solution interface can occur as a result of substitutional adsorption process between organic molecules presented in the aqueous solution $\left(\mathrm{Org}_{(\mathrm{sol})}\right)$, and the water molecules previously adsorbed on the metallic surface $\left(\mathrm{H}_{2} \mathrm{O}_{(\mathrm{ads})}\right)$ [29]:

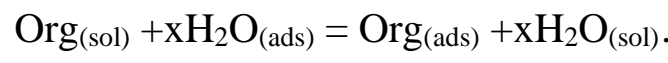

where $\operatorname{Org}_{(\text {sol) }}$ and $\operatorname{Org}_{(\text {ads })}$ are the organic species in the bulk solution and adsorbed one on the metallic surface, respectively, $\mathrm{H}_{2} \mathrm{O}_{(\text {ads })}$ is the water molecule adsorbed on the metallic surface and $\mathrm{x}$ is the size ratio representing the number of water molecules replaced by one organic adsorbate. In order to obtain the adsorption isotherm, the degree of surface coverage, $\theta$, for different concentrations of inhibitor in $1 \mathrm{M} \mathrm{H}_{2} \mathrm{SO}_{4}$ solution has been evaluated by equation (5). The $\theta$ values are presented in Table (7). According to the Langmuir's isotherm, the surface coverage $(\theta)$ is related to inhibitor concentration (C) by the following equation [30]:

$\frac{\mathbf{C}}{\boldsymbol{\theta}}=\frac{1}{\mathrm{~K}_{\mathrm{ads}}}+\mathbf{C}$

Where $K_{a d s}$ is the equilibrium constant of the inhibitor adsorption process. A straight line is obtained on plotting $\mathrm{C} / \theta$ versus $\mathrm{C}$ as shown in Fig. (4). The linear correlation coefficient $\left(r^{2}\right)$ is equal to $\left(r^{2}=0.9988-1\right)$ and the slope is very close to 1 , indicating the adsorption of synthesized inhibitor (STU3) on the carbon steel surface obeys the Langmuir adsorption isotherm. The high correlation facter $\left(\mathrm{r}^{2}\right)$ of the Langmuir adsorption isotherm may confirm the validity of this approach. The equilibrium constant $\left(\mathrm{K}_{\mathrm{ads}}\right)$ for the adsorption-desorption process of tested inhibitor can be calculated from reciprocal of the intercept. The adsorptive equilibrium constant $\left(\mathrm{K}_{\mathrm{ads}}\right)$ values are listed in Table (7). The most important thermodynamic adsorption parameters are the free energy of an adsorption $\left(\Delta \mathrm{G}_{\mathrm{ads}}\right)$ at different temperatures was calculated from the following equation [31]:

$$
\Delta \mathbf{G}_{\mathrm{ads}}=-2.303 \mathrm{RT} \log \left(55.5 \mathrm{~K}_{\mathrm{ads}}\right) \text {. }
$$

where $\mathrm{R}$ is the gas constant, $\mathrm{T}$ is the absolute temperature and the value 55.5 is the concentration of water in solution expressed in $\mathrm{M}, \mathrm{K}_{\mathrm{ads}}$ is the equilibrium constant of the inhibitor adsorption process .Values of $\Delta \mathrm{G}_{\mathrm{ads}}$ are listed in Table (7). The values of $\Delta \mathrm{G}_{\mathrm{ads}}$ negative sign are usually characteristic of a strong interaction and a high efficient adsorption. Generally, values of $\Delta \mathrm{G}_{\mathrm{ads}}$ around $20 \mathrm{~kJ} \mathrm{~mol}^{-1}$ or lower negative are consistent with the electrostatic interaction between the charged molecules and the charged metal (physisorption). Whereas, the more negative values than $-40 \mathrm{~kJ} \mathrm{~mol}{ }^{-1}$ involve charge sharing or transfer from the inhibitor molecules to the metal surface to form a 
coordinate type of bond (chemisorption) [32]. Calculated $\Delta \mathrm{G}_{\mathrm{ads}}$ values indicate that the adsorption mechanism of the synthesized
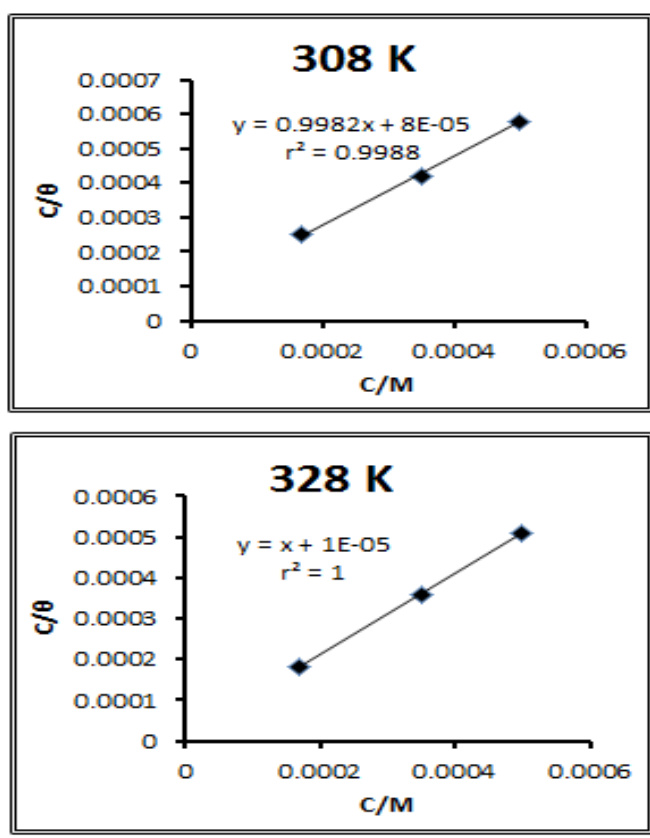

inhibitor on carbon steel in $1 \mathrm{M} \mathrm{H}_{2} \mathrm{SO}_{4}$ solution is chemical adsorption.
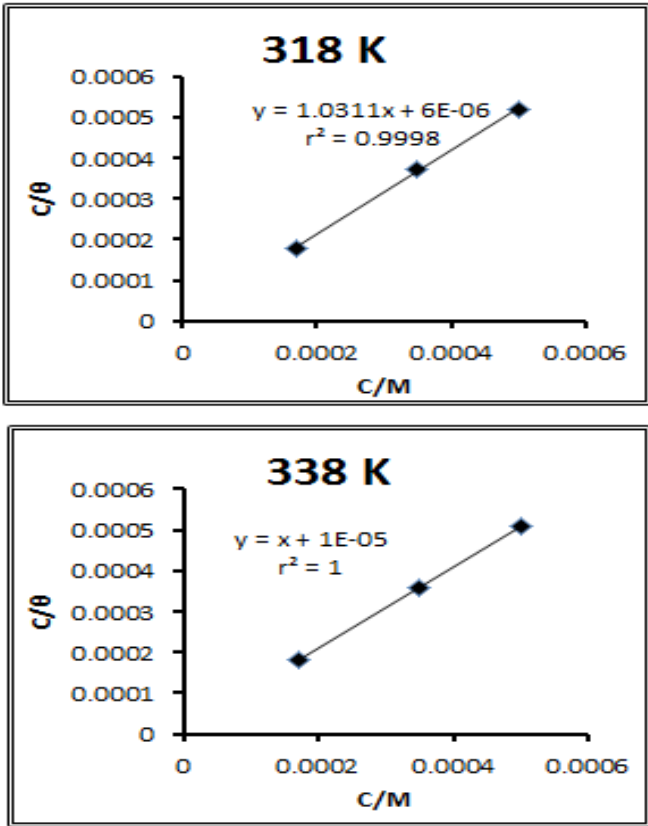

Fig.(4) The Langmuir isotherm adsorption for carbon steel in $1 \mathrm{M}_{2} \mathrm{HO}_{4}$ in the different concentrations of inhibitor (STU3) at (308-338) $\mathrm{K}$.

Table (7)

Data of free energy of adsorption and the parameter of adsorption isotherm for carbon steel in $\mathrm{IM} \mathrm{H}_{2} \mathrm{SO}_{4}$ solution in different concentrations of inhibitor (STU3) at (308-338) K.

\begin{tabular}{|c|c|c|c|c|c|c|c|}
\hline$T / K$ & $(1 / T)^{*} 10^{-3} K^{-1}$ & $C / M$ & $\theta$ & $C / \theta$ & $\boldsymbol{K}_{\text {ads }}\left(\boldsymbol{M}^{-1}\right)$ & $\begin{array}{c}\Delta G_{a d s} \\
K^{\prime} \text { mol }^{-1}\end{array}$ & $r^{2}$ \\
\hline \multirow{3}{*}{308} & \multirow{3}{*}{3.2} & $1.7 \times 10^{-4}$ & 0.6852 & 0.00025 & \multirow{3}{*}{12500} & \multirow{3}{*}{-34.44} & \multirow{3}{*}{0.9988} \\
\hline & & $3.5 \times 10^{-4}$ & 0.8370 & 0.00042 & & & \\
\hline & & $5 \times 10^{-4}$ & 0.8572 & 0.00058 & & & \\
\hline \multirow{3}{*}{318} & \multirow{3}{*}{3.1} & $1.7 \times 10^{-4}$ & 0.9310 & 0.00018 & \multirow{3}{*}{166666} & \multirow{3}{*}{-42.42} & \multirow{3}{*}{0.9998} \\
\hline & & $3.5 \times 10^{-4}$ & 0.9403 & 0.00037 & & & \\
\hline & & $5 \times 10^{-4}$ & 0.9578 & 0.00052 & & & \\
\hline \multirow{3}{*}{328} & \multirow{3}{*}{3.0} & $1.7 \times 10^{-4}$ & 0.9657 & 0.00018 & \multirow{3}{*}{100000} & \multirow{3}{*}{-42.36} & \multirow{3}{*}{1} \\
\hline & & $3.5 \times 10^{-4}$ & 0.9681 & 0.00036 & & & \\
\hline & & $5 \times 10^{-4}$ & 0.9810 & 0.00051 & & & \\
\hline \multirow{3}{*}{338} & \multirow{3}{*}{2.9} & $1.7 \times 10^{-4}$ & 0.9679 & 0.00018 & \multirow{3}{*}{100000} & \multirow{3}{*}{-43.65} & \multirow{3}{*}{1} \\
\hline & & $3.5 \times 10^{-4}$ & 0.9685 & 0.00036 & & & \\
\hline & & $5 \times 10^{-4}$ & 0.9856 & 0.00051 & & & \\
\hline
\end{tabular}

\section{Effect of temperature}

The change in the rate of the corrosion process with temperature was studied in $1 \mathrm{M}$ $\mathrm{H}_{2} \mathrm{SO}_{4}$ with and without (STU3) inhibitor at various concentrations $\left(1.7 \times 10^{-4}-5 \times 10^{-4}\right) \mathrm{M}$. The aim was to evaluate the apparent activation energy and the pre-exponential
Factor (A) of the corrosion process. This was carried out by studying the temperature dependence of the corrosion current obtained with the potentiostatic polarization method. The polarization exhibits Tafel behaviour. The Polarisation curves which are not presented here show that both the anodic and cathodic 
polarizations decrease upon heating while $\mathrm{I}_{\text {corr }}$ increases. Several electrochemical Parameters were calculated from these curves and the results are summarised in Table (8). I $\mathrm{I}_{\text {corr }}$ increases upon heating both in uninhibited and inhibited solutions. The Efficiency of STU3 increases with temperature increase in the studied temperature range. The fact that (\%IE) increases with temperature was considered by Ivanov [33] as due to Change in the nature of the adsorption mode. The inhibitor is physically adsorbed at lower temperatures, while Chemisorption is favoured at higher temperatures Fig. (5).

\section{Table (8)}

The effect of temperature on the corrosion parameters of carbon steel in $1 \mathrm{M} \mathrm{H}_{2} \mathrm{SO}_{4}$ containing different concentrations of inhibitor (STU3).

\begin{tabular}{|c|c|c|c|c|c|c|c|c|c|}
\hline $\begin{array}{c}\text { Conc. } \\
(M)\end{array}$ & $\underset{K}{\text { Temp. }}$ & $\begin{array}{c}E_{c o r r} \\
M v \\
(S C E) \\
\end{array}$ & $\begin{array}{c}I_{\text {corr }} \\
\mu A / \mathrm{cm}^{2}\end{array}$ & $\begin{array}{c}\beta c \\
m V / d e c\end{array}$ & $\begin{array}{c}\beta a \\
m V / d e c\end{array}$ & $\begin{array}{c}W . L \\
g / m^{2} . d\end{array}$ & $\begin{array}{c}\text { Penetration } \\
\text { loss } \\
\mathrm{mm} / \mathrm{a} \\
\end{array}$ & $\theta$ & $\% I E$ \\
\hline 0 & $\begin{array}{l}308 \\
318 \\
328 \\
338 \\
\end{array}$ & $\begin{array}{l}-411.8 \\
-394.7 \\
-381.2 \\
-372.3 \\
\end{array}$ & $\begin{array}{c}1450 \\
6150 \\
13390 \\
21510 \\
\end{array}$ & $\begin{array}{l}-109.2 \\
-134.4 \\
-153.6 \\
-243.2 \\
\end{array}$ & $\begin{array}{c}70.5 \\
102.6 \\
128.8 \\
137.4 \\
\end{array}$ & $\begin{array}{c}363 \\
1540 \\
3350 \\
5380 \\
\end{array}$ & $\begin{array}{l}16.9 \\
71.4 \\
155 \\
250 \\
\end{array}$ & -- & -- \\
\hline $1.7 \times 10^{-4}$ & $\begin{array}{l}308 \\
318 \\
328 \\
338 \\
\end{array}$ & $\begin{array}{l}-454.9 \\
-438.9 \\
-432.1 \\
-421.7 \\
\end{array}$ & $\begin{array}{l}456.44 \\
424.14 \\
458.46 \\
688.68 \\
\end{array}$ & $\begin{array}{l}-151.8 \\
-147.4 \\
-110.3 \\
-74.6 \\
\end{array}$ & $\begin{array}{l}123.5 \\
109.1 \\
104.1 \\
77.7 \\
\end{array}$ & $\begin{array}{l}114 \\
106 \\
115 \\
172 \\
\end{array}$ & $\begin{array}{l}5.30 \\
4.92 \\
5.32 \\
7.99 \\
\end{array}$ & $\begin{array}{l}0.68 \\
0.93 \\
0.96 \\
0.96 \\
\end{array}$ & $\begin{array}{l}68.52 \\
93.10 \\
96.57 \\
96.79 \\
\end{array}$ \\
\hline $3.5 \times 10^{-4}$ & $\begin{array}{l}308 \\
318 \\
328 \\
338 \\
\end{array}$ & $\begin{array}{l}-448.4 \\
-441.7 \\
-440.0 \\
-432.0 \\
\end{array}$ & $\begin{array}{l}236.24 \\
366.72 \\
426.46 \\
675.42 \\
\end{array}$ & $\begin{array}{l}-112.0 \\
-119.6 \\
-88.4 \\
-101.1 \\
\end{array}$ & $\begin{array}{l}105.1 \\
104.4 \\
70.5 \\
83.0 \\
\end{array}$ & $\begin{array}{l}59.1 \\
91.7 \\
107 \\
169 \\
\end{array}$ & $\begin{array}{l}2.74 \\
4.26 \\
4.95 \\
7.84 \\
\end{array}$ & $\begin{array}{l}0.83 \\
0.94 \\
0.96 \\
0.96 \\
\end{array}$ & $\begin{array}{l}83.70 \\
94.03 \\
96.81 \\
96.85 \\
\end{array}$ \\
\hline $5 \times 10^{-4}$ & $\begin{array}{l}308 \\
318 \\
328 \\
338\end{array}$ & $\begin{array}{l}-458.8 \\
-440.5 \\
-433.6 \\
-423.4\end{array}$ & $\begin{array}{l}206.92 \\
259.22 \\
253.11 \\
307.77\end{array}$ & $\begin{array}{l}-73.6 \\
-110.2 \\
-107.8 \\
-123.0\end{array}$ & $\begin{array}{l}64.4 \\
89.1 \\
93.0 \\
90.6\end{array}$ & $\begin{array}{l}51.7 \\
64.8 \\
63.3 \\
76.9\end{array}$ & $\begin{array}{l}2.40 \\
3.01 \\
2.94 \\
3.57\end{array}$ & $\begin{array}{l}0.85 \\
0.95 \\
0.98 \\
0.98\end{array}$ & $\begin{array}{l}85.72 \\
95.78 \\
98.10 \\
98.56\end{array}$ \\
\hline
\end{tabular}

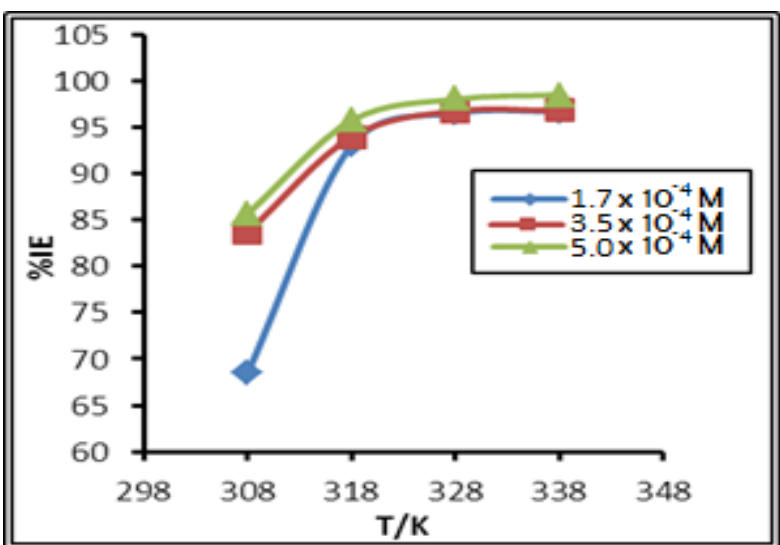

Fig.(5) Relationship between inhibition efficiencies and different temperature(308338) $\mathrm{K}$ for carbon steel in $\mathrm{IM} \mathrm{H}_{2} \mathrm{SO}_{4}$ for inhibitor(STU3).

Although the adsorption process was sufficiently elucidated by the thermodynamic model, the kinetic model is another way to explain the mechanism of corrosion inhibition. The corrosion reaction can be regarded as an Arrhenius modified Arrhenius equation [28]: $\log i_{\text {corr }}=\log A-\frac{E_{a}^{*}}{2.303 R T}$

Where $\mathrm{i}_{\text {corr }}$ is the corrosion current density, $E_{a}^{*}$ is the apparent activation energy of the corrosion reaction, $\mathrm{R}$ is the gas constant, $\mathrm{T}$ is the absolute temperature and $\mathrm{A}$ is the Arrhenius pre-exponential factor. Fig.(6) presents the Arrhenius plots of the natural logarithm of the current density $v s 1 / \mathrm{T}$, for $1 \mathrm{M}$ solution of $\mathrm{H}_{2} \mathrm{SO}_{4}$, in presence and absence of different concentrations of compound (STU3).

Values of $E_{a}^{*}$ and $\mathrm{A}$ for the corrosion reaction in the absence and presence of different concentrations of the (STU3) inhibitor are calculated by a linear regression method and given in Table (9). It is found that the activation energy is lower in the presence of inhibitor than in its absence.

Enthalpy and entropy of activation $\left(\Delta \mathrm{H}^{*}\right.$ and $\left.\Delta \mathrm{S}^{*}\right)$ are calculated from the transition state equation [34]:

$\log \left(\frac{i_{\text {corr }}}{T}\right)=\left(\log \left(\frac{R}{N_{A} h}\right)+\left(\frac{\Delta S^{*}}{2.303 R}\right)\right)-\frac{\Delta H^{*}}{2.303 R} \times \frac{1}{T}$ 
where $h$ is Planck's constant, $\mathrm{N}_{\mathrm{A}}$ is Avogadro's number, $\mathrm{R}$ is the universal gas constant, $\Delta H^{*}$ is the enthalpy of the activation and $\Delta S^{*}$ is the entropy of activation. Plotting of $\log \left(\mathrm{i}_{\text {corr }} / \mathrm{T}\right.$ ) against $1 / \mathrm{T}$, (Eq. (8)), for carbon steel in $1 \mathrm{M} \mathrm{H}_{2} \mathrm{SO}_{4}$ in the absence and presence of different concentrations from the synthesized inhibitor, gives straight lines as shown in Fig. (7). Data in Table (9) represent the values of $\Delta H^{*}$ and $\Delta S^{*}$ which are calculated from the slope $\left(-\Delta H^{*} / 2.303 \mathrm{R}\right)$ and the intercept $\left[\log \left(\mathrm{R} / \mathrm{N}_{\mathrm{A}} \mathrm{h}\right)+\Delta S^{*} / 2.303 \mathrm{R}\right]$ of the straight lines. Values of $\Delta H^{*}$ and $\Delta S^{*}$ are calculated and listed in Table (9).

$E_{a}^{*} \quad$ decreases with increasing the synthesized inhibitor (STU3) concentration. It is obvious that concentration of the synthesized inhibitor is playing a role in decreasing the activation energy value, thereby indicating a more efficient inhibiting effect. The decrease in $E_{a}^{*}$ with the synthesized inhibitor concentration is typical of chemisorption process [35]. This was attributed by Hoar and Holliday [36] to a slow rate of inhibitor adsorption with a resultant closer approach to equilibrium during the experiments at the higher temperature. But, Riggs and Hurd [37] explained that the decrease in activation energy of corrosion at higher levels of inhibition arises from a shift of the net corrosion reaction from that on the uncovered part on the metal surface to the covered one. Schmid and Huang [38] found that organic molecules inhibit both the anodic and cathodic partial reactions on the electrode surface and a parallel reaction takes place on the covered area, but that the reaction rate on the covered area is substantially less than on the uncovered area like that in this work Table (9). According to Eq. (7) low values of A and high values of $E_{a}^{*}$ lead to lower corrosion rates. For the present study, $E_{a}^{*}$ is lower in the presence of (STU3). Therefore, the decrease in the steel corrosion rate is decided by the pre-exponential factor $\mathrm{A}$, which reflects the effect of the variation of entropy $\Delta S^{*}$ during activation. It was found that $\mathrm{A}$ and consequently $\Delta S^{*}$ significantly decreased with inhibitor concentration reducing the corrosion rate of the steel. As a result, the corrosion rate of steel decreased with increasing inhibitor concentration. Clearly, the reduction of $\mathrm{A}$ is an important factor that determines the corrosion rate of steel in $1 \mathrm{M} \mathrm{H}_{2} \mathrm{SO}_{4}$ in the presence of (STU3). Generally one can say that the nature and the concentration of electrolyte affect greatly the activation energy for the corrosion process.

The positive signs of the enthalpy $\Delta H^{*}$ reflect denoting that transition state (the activated complex) is endothermic process. Negative values of entropies $\Delta S^{*}$ and addition to the value of $\Delta S^{*}$ decreases gradually with increasing the synthesized inhibitor concentrations imply that the activated complex in the rate determining step represents an association rather than a dissociation step. This meaning that a decrease in disordering takes place on going from reactants to the activated complex $[39,40]$.

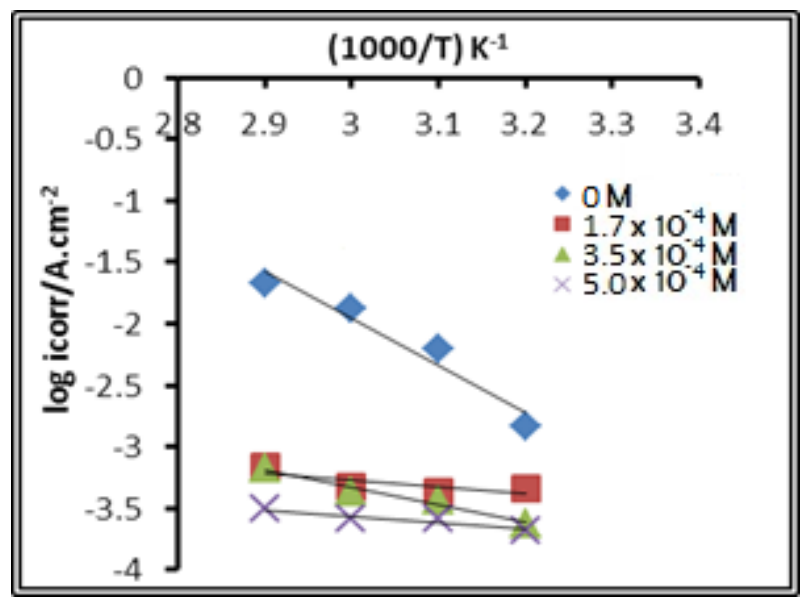

Fig. (6) Arrhenius plots of log $i_{\text {corr }}$ versus $1 / T$ in presence and absence of different concentrations of inhibitor (STU3).

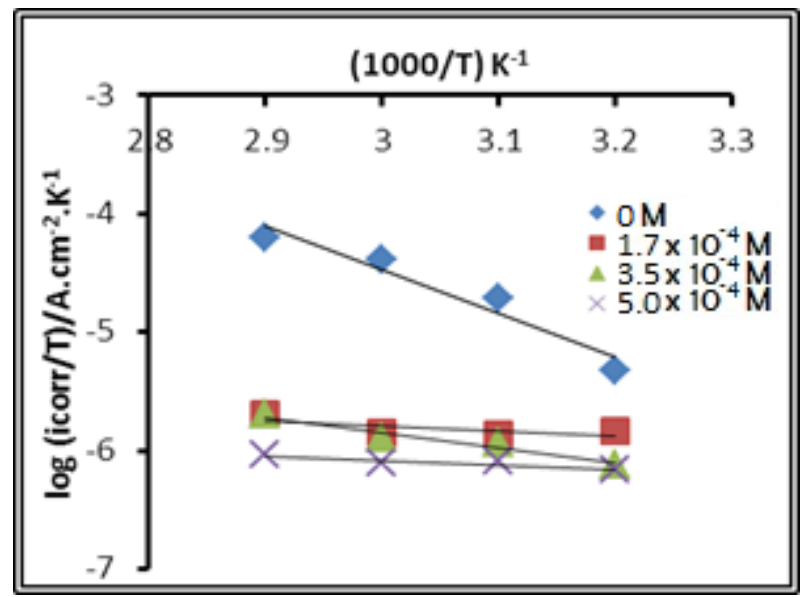

Fig. (7) Arrhenius plots of log $\left(i_{\text {corr }} / T\right)$ versus 1/T for carbon steel in $1 \mathrm{M} \mathrm{H}_{2} \mathrm{SO}_{4}$ solution without and with different concentrations of the inhibitor (STU3). 
Table (9)

The thermodynamic parameters of activation of the synthesized inhibitor (STU3) at different concentrations for carbon steel in $\mathrm{IM} \mathrm{H}_{2} \mathrm{SO}_{4}$.

\begin{tabular}{|c|c|c|c|c|}
\hline $\begin{array}{l}C \\
M\end{array}$ & $\begin{array}{c}A \\
A . \mathrm{cm}^{-2}\end{array}$ & $\begin{array}{c}E_{a}^{*} \\
\text { KJ.mol }{ }^{-1}\end{array}$ & $\begin{array}{c}\Delta H^{*} \\
\text { KJ.mol }{ }^{-1}\end{array}$ & $\begin{array}{c}\Delta S^{*} \\
J . \mathrm{mol}^{-1} \cdot K^{-1}\end{array}$ \\
\hline$\overline{0}$ & $3.9 \times 10^{9}$ & 73.74 & 71.04 & -950.86 \\
\hline $1.7 \times 10^{-4}$ & $2.94 \times 10^{-2}$ & 11.1 & 8.42 & -1163.89 \\
\hline $3.5 \times 10^{-4}$ & $799 \times 10^{-2}$ & 26.9 & 25.08 & -1115.04 \\
\hline $5 \times 10^{-4}$ & $0.860 \times 10^{-2}$ & 9.57 & 7.08 & -1173.58 \\
\hline
\end{tabular}

\section{Conclusion}

The inhibiting effect of N-Aroyl-N'-Aryl thiourea derivatives (STU1-3) in $1 \mathrm{M} \mathrm{H}_{2} \mathrm{SO}_{4}$ on carbon steel was studied by various methods. The results are in good agreement and the main conclusions are as follows.

1. The chemical structure of the synthesized inhibitors are confirmed by FTIR, ${ }^{1} \mathrm{H}-\mathrm{NMR}$ and ${ }^{13} \mathrm{C}-\mathrm{NMR}$.

2. The corrosion inhibition efficiency (\% IE) of thiourea derivatives follows the sequence: STU3 > STU2 > STU1.

3. STU3 was found to be the best inhibitor for carbon steel in $1 \mathrm{M} \mathrm{H}_{2} \mathrm{SO}_{4}$.

4. The inhibition efficiency of STU3 increases with increase of inhibitor concentration. Its presence in the solution decreases the value of the apparent activation corrosion energy.

5. The adsorption of STU3 on the steel surface in sulphuric acid obeys the Langmuir adsorption isotherm model and leads to the formation of a protective film.

6. The analysis of the experimental data leads to the suggestion of chemisorption of the inhibitor on the metal surface. In fact, the apparent activation energy of the corrosion that is lower in presence of STU3 than in its absence and the higher values of the free energy of adsorption verify the chemisorptive character of the adsorption.

7. The substance is adsorbed with the heteroatoms forming donor-acceptor bonds between unpaired electrons of the heteroatoms and the active centres of the metal surface.

\section{Acknowledgement}

The authors express their sincere thanks for petroleum research \& development center [ministry of oil / Iraq] for their financial and scientifically support, also special thanks for Dr. Kareem M. Ali Al-Samuraee [University of Baghdad/ College of Science/ Dept. of Chemistry] for his helpful in measurement of corrosion.

\section{References}

[1] Deyab, M.A., "Effect of cationic surfactant and inorganic anions on the electrochemical behavior of carbon steel in formation water", Corros. Sci., vol. 49, pp. 23152328, 2007.

[2] Bentiss, F., Traisnel, M. and Lagrenee, M., "Thesubstituted 1,3,4-oxadiazoles: a new class of corrosion inhibitors of mild steel in acidicmedia", Corros. Sci., vol.42, pp.127146, 2000.

[3] Khaled, K.F., "Application of electrochemical frequency modulation for monitoring corrosion and corrosion inhibition of iron by some indole derivatives in molar hydrochloric acid", Mater.Chem. Phys., vol.112, pp. 290-300, 2008.

[4] Machnikova, E., Whitmire, K.H. and Hackerman, N., "Corrosion inhibition of carbon steel in hydrochloric acid by furan derivatives", Electrochim. Acta, vol.53, pp. 6024-6032, 2008.

[5] Migahed, M.A. and Nassar, I.F., "Corrosion inhibition of Tubing steel during acidization of oil and gas wells", Electrochimica Acta, vol.53, pp. 28772882, 2008.

[6] Abd El-Maksoud, S.A. and Fouda, A.S., "Some pyridine derivatives as corrosion 
inhibitors for carbon steel in acidic medium", Mater. Chem. Phys., vol.93, pp. 84-90, 2005.

[7] Memari, B., Elattari, H., Traisnel, M., Bentiss, F., and Lagrenee, M., "Inhibiting effects of 3,5-corrosion for mild steel in $1 \mathrm{M}$ $\mathrm{HCl}$ medium", Corros. Sci., vol.40, pp. 391-399, 1998.

[8] Mamosemh, M., Jizhou, D. And Xiangqian, D., "Investigation of the effect of 4,5-dichloro-2-n-octyl-4-isothiazolin-3one inhibition on the corrosion of carbon steel in Bacillus sp. Inoculated artificial seawater", Corros.Sci., vol. 69, pp. 338345, 2013.

[9] Lagrenee, M., Mernari, B., Bouanis, M., Traisnel, M. And Bentiss, F., "Study of the mechanism and inhibiting efficiency of 3,5bis(4-metylthiophenyl)-4H-1,2,4-triazole on mild steel corrosion in acidic media", Corros. Sci., vol.44, pp. 573-588, 2002.

[10] Abboud, Y., Abourriche, A., Saffaj, T., Berrada, M., Charrouf, M., Bennamara, A., Al Himidi, N. And Hannache, H.," 2,3Quinoxalinedione as a novel corrosion inhibitor for mild steel in $1 \mathrm{M} \mathrm{HCl}$ ", Mater Chem. Phys., vol.105 , pp. 1-5, 2007.

[11] S. Divakara Shetty, Prakash Shetty, H.V. Sudhaker Nayak, "The inhibition action of $\mathrm{N}$ - (furfuryl)-N'-phenyl thiourea on the corrosion of mild steel in hydrochloric acid medium", Mater. Lett. Vol.61, PP. 2347-2349, 2007.

[12] Abd El-Aziz, F. and Ahmed, H., "Role of Some Phenylthiourea Derivatives as Corrosion Inhibitors for Carbon Steel in $\mathrm{HCl}$ Solution", Journal of the Korean Chemical Society, Vol. 56, No. 2, pp. 264-273, 2012.

[13] Shen, C.B., Wang, S.G., Yang, H.Y., Long, K. and Wang, F.H., "Corrosion and corrosion inhibition by thiourea of bulk nanocrystallized industrial pure iron in dilute $\mathrm{HCl}$ solution", Corros. Sci., vol. 48, pp. 1655-1665, 2006.

[14] Loto, R.T., Loto, C.A., Popoola, A.P.I., "corrosion inhibition of thiourea and thiadiazole derivatives : A Review", J. Mater. Environ. Sci. vol. 3, No.5, pp. 885-894, 2012.
[15] Tripathi R.,Chaturvedi A. and Upadhayay R.K., "Corrosion Inhibitory Effects of Some Substituted Thiourea on Mild Steel In Acid Media", Research Journal of Chemical Sciences, Vol. 2, No.2, pp. 1827, 2012.

[16] Mahgoub, F.M., "Effect of protonation on the inhibition efficiency of thiourea and its derivatives As corrosion inhibitors", Anti-Corrosion Methods and Materials, Vol. 55, Iss. 6, pp. 324-328. 2008.

[17] Khaled, K.F. "Experimental, density function theory calculations and molecular dynamics simulations to investigate the adsorption of some thiourea derivatives on iron surface in nitric acid solutions", Appl. Surf. Sci., vol. 256, pp. 6753-6763, 2010.

[18] Benali, O., Larabi, L.and Harek, Y., "Adsorption and inhibitive corrosion properties of thiourea derivatives on cold rolled steel in $1 \mathrm{M} \mathrm{HClO}_{4}$ solutions", J. Appl. Electrochem., vol. 39, pp. 769-778, 2009.

[19] Xianghong, L., Shuduan, D. and Hui, F., "Allyl thiourea as a corrosion inhibitor for cold rolled steel in $\mathrm{H}_{3} \mathrm{PO}_{4}$ solution", Corrosion Science, vol $\mathrm{xxx}, \mathrm{pp} . \mathrm{xxx}-\mathrm{xxx}$, 2011.

[20] Khamis, A., Saleh, M.M. and Awad, M.I., "Synergistic inhibitor effect of cetylpyridinium chloride and other halides on the corrosion of mild steel in $0.5 \mathrm{M}$ $\mathrm{H}_{2} \mathrm{SO}_{4} "$, Corros. Sci., vol. 66, pp. 343-349, 2013.

[21] Marian, B., Andrea, K., Jean-Pièrre, M., Cornelia M., Nicolae V., "Corrosion resistance of carbon steel in weak acid solutions in the presence of L-histidine as corrosion inhibitor", Corros Sci., vol.69, pp. 389-395, 2013.

[22] Hegazy, M.A., Badawi, A.M., Abd El Rehim, S.S.and Kamel,W.M.,"Corrosion inhibition of carbon steel using novel N-(2(2-mercaptoacetoxy)ethyl)-N,N-dimethyl dodecan-1-aminium bromide during acid pickling", Corros.Sci., vol.69,pp. 110-122, 2013. 
[23] Aamer, S., Naeem, A., Hummera, R., Sadaf R. and Hameed, A., "synthesis characterization and antibacterial activity of some 1-aroyl-3-aryl thioureas", chemistry, vol. 18, iss. 5, pp. 152-158, 2009.

[24] Silverstein,R.M. and Bassler, G.C., "Spectrometric identification of organic compounds", 4 ${ }^{\text {th }}$ Edition, John and Son, 1981.

[25] Yaro, A.S., Khadom, A.A. and Ibraheem,H.F., "Peach juice as an anticorrosion inhibitor of mild steel", Anti Corros. Meth.Mater., vol.58 , pp. 116-124, 2011.

[26]Igahed, M.A., Attya, M.M., Rashwan, S.M., Abd El-Raouf, M. and Al-Sabagh A.M., "Synthesis of some novel non ionic surfactants based on tolyltriazole and valuation their performance as corrosion inhibitors for carbon steel", Egyptian Journalof Petroleum, vol.xxx, pp. xxxxxx, 2013.

[27] Issaadi, S., Douadi, T., Zouaoui, A., Chafaa, S., Khan, M.A. and Bouet, G., "Novel thiophene symmetrical Schiff base compounds as corrosion inhibitor for mild steel in acidic media",Corros. Sci., vol.53, pp. 1484-1488, 2011.

[28] Omar, B., Lahcene, L., Salah, M. and Yahia, H. ,"Influence of the Methylene Blue Dye (MBD) on the corrosion inhibition of mild steel in $0.5 \mathrm{M}$ sulphuric acid, Part I:weight loss and electrochemical studies", J.Mater. Environ. Sci., vol.2, No.1, pp. 39-48, 2011.

[29] Bouklah, M., Hammouti, B., Lagrenée, M.and Bentiss, F., "Thermodynamic properties of 2,5-bis(4-methoxyphenyl)1,3,4-oxadiazole as a corrosion inhibitor for mild steel in normal sulfuric acid medium", Corros. Sci., vol.48, pp. 28312842, 2006.

[30] Labjar, N., Lebrini, M., Bentiss, F., Chihib, N., El Hajjaji, S. and Jama, C., "Corrosion inhibition of carbon steel and antibacterial properties of aminotrisethylenephosphonic)acid", Mater. Chem. Phys., vol. 119, pp. 330-336, 2010.
[31] Yati, N.S., Khandandel, S., Momeni, M., Moayed, M.H., Davoodi, A. and Rahimizadeh, M., "Inhibitive effect of synthesized 2-(3-pyridyl)- 3,4-dihydro-4quinazolinone as a corrosion inhibitor for mild steel in hydrochloric acid", Mater. Chem. Phys., vol.126, pp. 873-879, 2011.

[32] Eshghi, H., Rahimizadeh, M., Shiri, A. and Sedaghat, P., "One-pot Synthesis of Benzimidazoles and Benzothiazoles in the Presence of $\mathrm{Fe}\left(\mathrm{HSO}_{4}\right)_{3}$ as a New and Efficient Oxidant Bul"1,Korean Chem. Soc., vol. 33 , pp. 515-518, 2012.

[33] Ivanov, E.S., "Inhibitions for metal corrosion in acid media" Metallurgy, Moscow, 1986. [34] Shukla, S.K. and Quraishi, M.A., "4-Substituted anilinomethylpropionate: new and efficient corrosion inhibitors for mild steel in hydrochloricacid solution", corros. Sci., vol.51, pp. 1990- 1997, 2009.

[35] Foroulis, Z.A., "Proceedings of the 7th European corrosion inhibitors", Ferrara, pp. 149, 1990.

[36] Hoar, T.P. and Holliday, R.D., "The inhibition by quinolines and thioureas of the acid dissolution of mild steel", J. Appl. Chem., vol.3, pp. 502-513, 1953.

[37] Riggs, L.O. and Hurd, T.J., "Temperature coefficient of corrosion inhibition", Corrosion, vol.23, pp. 252-258, 1967.

[38] Schmid, G.M. and Huang, H.J., "Spectroelectrochemical studies of the inhibition effect of 4,7-diphenyl-1,10-phenanthroline on the corrosion of 304stainless steel", Corros. Sci., vol.20, pp.1041-1057, 1980.

[39] Marsh, J., "Advanced Organic Chemistry", third ed., Wiley Eastern, New Delhi, 1988.

[40] Martinez, S. Stern, and I., "Thermodynamic characterization of metal dissolution and inhibitor adsorption processes in the low carbon steel/mimosa tannin/sulfuric acid system", Appl. Surf. Sci., vol.199, pp. 83-89, 2002. 
يتضمن البحث تحضير بعض مشتقات الثايويوريا

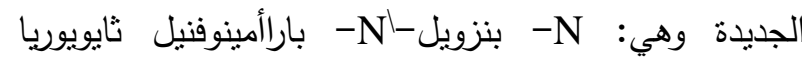

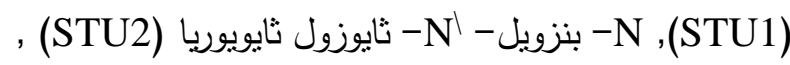
-N اسيتايل - N -N

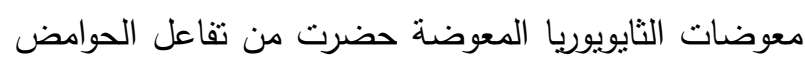

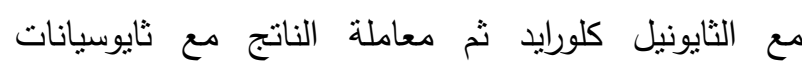
البوتاسيوم لتعطي مشتقات الثايوسيانات التي تتفاعل مباشرة مع أمينات اروماتية اولية وثانوية. نم تتقية المركبات المحضرة وأثباتها عن طريق قياس درجة الانصهار، TLC كما تم تشخيص التراكيب بواسطة الطرائق الطيفية [FTIR, ${ }^{1} \mathrm{H}-\mathrm{NMR}$ and ${ }^{13} \mathrm{C}-\mathrm{NMR}$ ] الثوابت الفيزياوية. تمت دراسة تأثنر المركبات المحضرة كمثبطات لتآكل حديد الصلب الكربوني في محيط 1 مولاري حامض الكبريتيك باستخدام تقنيتي فرق الوزن وطريقة قياس

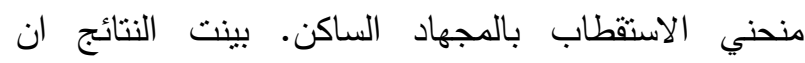

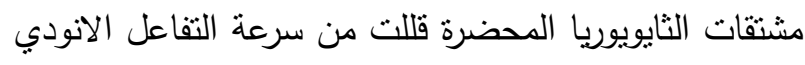
والكانودي على حدّ سواء في المحيط الحامضي وان هذه الاعاقة ناتجة من أمثزازها على سطح الفولاذ. وعملية الأمتزاز

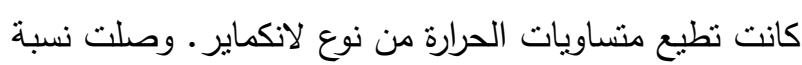

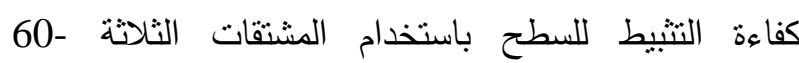
\%(95). تمت دراسة تأثثر نراكيز مختلفة من المشتق

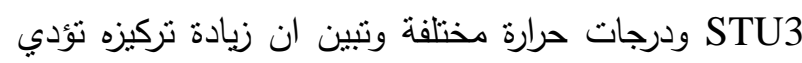
الى زيادة كفاءة التثبط ووصلت أعلى نسبة

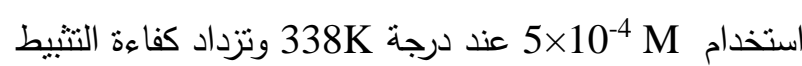
بزيادة درجات الحرارة 308-338)K). 